\title{
Strategies for improving fertilizer phosphorus use efficiency in Chinese cropping systems
}

\author{
Gu FENG (凶) ${ }^{1}$, Jingping GAI ${ }^{1}$, Xionghan FENG ${ }^{2}$, Haigang $\mathrm{LI}^{1}$, Lin $\mathrm{ZHANG}^{1}$, Keke $\mathrm{YI}^{3}$, Jialong $\mathrm{LV}^{4}$, \\ Yiyong $\mathrm{ZHU}^{5}$, Li TANG ${ }^{6}$, Yilin $\mathrm{LI}^{7}$ \\ 1 College of Resources and Environmental Sciences, China Agricultural University, Beijing 100193, China \\ 2 College of Resources and Environment, Huazhong Agricultural University, Wuhan 430070, China \\ 3 Key Laboratory of Plant Nutrition and Fertilizer, Ministry of Agriculture, Institute of Agricultural Resources and Regional Planning, \\ Chinese Academy of Agricultural Sciences, Beijing 100081, China \\ 4 College of Natural Resources and Environment, Northwest A\&F University, Yangling 712100, China \\ 5 College of Resources and Environmental Sciences, Nanjing Agricultural University, Nanjing 210095, China \\ 6 College of Resources and Environmental Sciences, Yunnan Agricultural University, Kunming 650201, China \\ 7 State Key Laboratory of Soil and Sustainable Agriculture, Institute of Soil Science, Chinese Academy of Sciences, Nanjing 210008, China
}

\begin{abstract}
A four-year project, entitled "The mechanisms of fraction transformation and high use efficiency of $\mathrm{P}$ fertilizer in Chinese cropping systems" commenced in 2017. The project was established to answer three key questions and looked at 17 cropping systems on ten soils. First, we asked what are the dynamics of transformation, fixation and mobilization of $\mathrm{P}$ fertilizers in soil-cropping systems? Second, what are the mechanisms of soil-cropmicrobe interactions by which $P$ fertilizer can be efficiently used? Third, how to manipulate the processes of $P$ use in cropping systems? The targets of this project are (1) to explore the mechanisms of $\mathrm{P}$ fixation, the pathways of loss of $P$ availability and the threshold of migration of fertilizer $P$ in the field; (2) to uncover mechanisms by which soil legacy $\mathrm{P}$ is mobilized through root physiological and morphological processes and through arbuscular mycorrhizal fungi and P-solubilizing bacteria in rhizosphere and hyphosphere; (3) to estimate the biological potential of crops for high efficiency $\mathrm{P}$ absorption and use; (4) to innovate new approaches for improving the efficiency of $P$ fertilizers. The outcomes will provide theoretical support for setting standards for limitation of $\mathrm{P}$ fertilizer application rate in the main cropping zones of China.
\end{abstract}

Keywords fixation, mobilization, phosphorus fertilizer, rhizosphere, transformations, utilization

Received May 6, 2019; accepted July 10, 2019

Correspondence: fenggu@cau.edu.cn

\section{Background}

Managing phosphorus use in agriculture, to ensure adequate food supply while protecting environmental quality, is a great challenge in China ${ }^{[1]}$. Over the past 60 years, in order to feed $22 \%$ of the global population, cereal grain production in China has increased nearly 6-fold from $110 \mathrm{Mt}$ in 1961 to $618 \mathrm{Mt}$ in $2017^{[2]}$. Although farming less than $9 \%$ of the world's arable land, China consumes $36 \%$ of the world's chemical P fertilizers ${ }^{[3]}$. In addition, the large increase in $\mathrm{P}$ fertilizer input has not been converted to corresponding photosynthetic production, but has rather caused substantial environmental pollution ${ }^{[4,5]}$. For example, between 1998 and 2009, grain yields increased by only $10 \%$, while chemical P fertilizer inputs increased by nearly $19 \%$. This suggests twice as much fertilizer $P$ is added than the $\mathrm{P}$ removed in harvested crops. Fertilizer $\mathrm{P}$ recovery in the above ground plant parts at maturity in Chinese cereal grain production decreased from about $35 \%$ in the 1980 s to $28 \%$ in the $2000 \mathrm{~s}^{[4]}$. Consequently, fertilizer $\mathrm{P}$ use efficiency in China is less than the global average ${ }^{[1,6-9]}$. Such fertilizer P surplus in soil causes severe environmental problems, i.e., eutrophication of surface waters. It is reported that $\mathrm{P}$ has become one of main causes of agricultural nonpoint source pollution, with $67 \%$ of $\mathrm{P}$ pollution derived from agriculture ${ }^{[10]}$.

Except for environmental issues, agriculture faces another major challenge, that is global rock $\mathrm{P}$ resource limitation. Studies claim that at the current rates of extraction, global commercial phosphate reserves will be depleted within $50-100$ years ${ }^{[11]}$. China is the second largest owner of rock $\mathrm{P}$ deposits. However, high-grade fossil $\mathrm{P}$ rock is being exhausted at nearly $12 \mathrm{Mt}_{2} \mathrm{O}_{5}$ per 
year primarily being converted into $\mathrm{P}$ fertilizers and applied to farmland ${ }^{[12]}$. Zhang et al. ${ }^{[4]}$ estimate that at this rate of extraction, Chinese rock $P$ resources will be exhausted within a few decades. Therefore, the development of novel strategies and techniques to improve fertilizer P efficiency in cropping systems is receiving considerable attention.

Fertilizer $\mathrm{P}$ applied to fields undergoes four processes in cropping systems: (1) sorption or precipitation with soil constituents; (2) mobilization of the immobilized fertilizer $\mathrm{P}$ through root physiological response; (3) mobilization of the immobilized fertilizer P by mycorrhizal fungi and Psolubilizing bacteria in rhizosphere and hyphosphere soils; and (4) P uptake by roots, storage in vacuoles and use in plants (Fig. 1). The immobilization of fertilizer $P$ has been found to be quite rapid. Availability to crops declines by $75 \%$ in $30 \mathrm{~d}$ due to adsorption to soil solids, precipitation by metal ions and occlusion by aluminum or ferric oxides $^{[13]}$.

As shown in Fig. 1, phosphorus experiences two mobilization processes and two immobilization processes when phosphate rock is converted into $\mathrm{P}$ fertilizer and the fertilizer is applied in soil-plant systems. First, phosphate rock is converted into water soluble forms by industrial processes. Second, while the highly concentrated $\mathrm{P}$ fertilizers are applied in soils, their water solubility will decline very quickly due to fixation. The bioavailability of fertilizer P then becomes the limiting factor. In response, plants invest photosynthate to reconstruct root morphological structure or to excrete exudates (carboxylates, phosphates, proton), to recruit arbuscular mycorrhizal fungi or phosphorus-solubilizing bacteria to reconvert the fixed $\mathrm{P}$ fertilizer. And finally, when $\mathrm{P}$ is taken up by roots or mycorrhizal hyphae it can be stored in vacuoles for later use. Matching the properties of the $\mathrm{P}$ fertilizer, soil chemical characteristics and plant requirement is crucial for highly efficient management of $\mathrm{P}$ fertilizer use.

Currently, the Chinese $\mathrm{P}$ fertilizer market is dominated by highly concentrated water-soluble and compounded fertilizers, such as ammonium phosphates which are used in various cropping systems including those on acidic or calcareous soils. The primary defect of $\mathrm{P}$ fertilizer use is that it rarely matches the demands of soil characteristics and cropping systems at the correct time and space. Results from long-term experiments and national soil surveys conducted in the 1980s and 2000s in China have shown that both the total soil $\mathrm{P}$ and available $\mathrm{P}$ (Olsen-P) have significantly increased, e.g., Olsen-P concentration in topsoil has increased from 7.4 to $24.7 \mathrm{mg} \cdot \mathrm{kg}^{-1[14]}$. To face the challenges posed by over fertilization of crops with P, the Ministry of Science and Technology of China launched the national key research and development project entitled "The mechanisms of fraction transformation and high use efficiency of P fertilizer in Chinese soilcropping systems". The main target is to provide new strategies and agronomic interventions to improve the use efficiency of phosphate fertilizer from $24 \%$ to $34 \%$, at the same time, to reduce the application rate of $\mathrm{P}$ fertilizer by $20 \%$ by 2020 .

To achieve this target, one of the most important issues is to increase the sustainability of nutrient use in intensive agriculture. Three key approaches are presented to address these challenges:

First, quantify the dynamics of $\mathrm{P}$ fertilizer use in cropping systems with particular emphasis on understanding impacts of soil microbe interactions on $\mathrm{P}$ fraction transformation in soil and the impact of soil $\mathrm{P}$ fixation and field runoff on the reduction in $\mathrm{P}$ use efficiency.

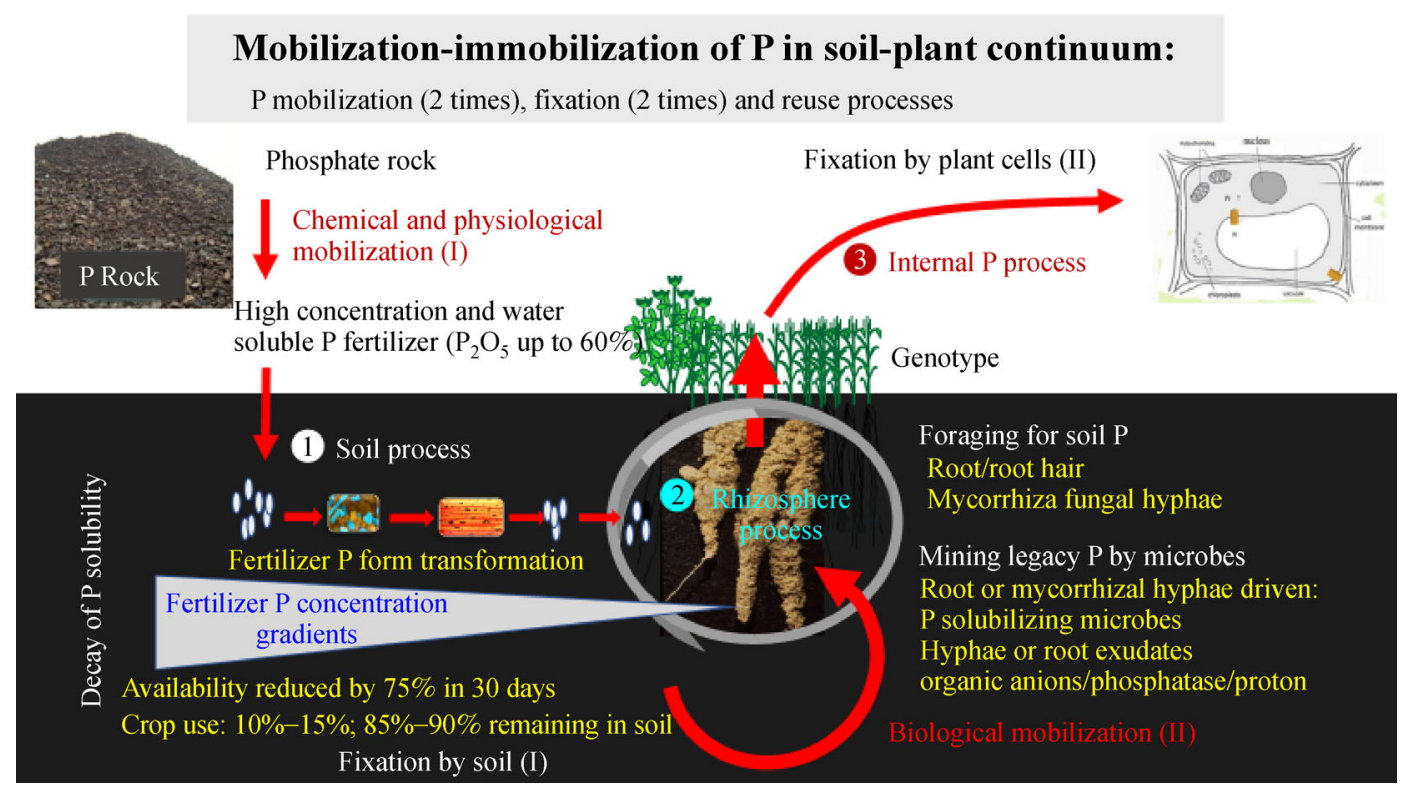

Fig. 1 The changes in availability of $\mathrm{P}$ from rock to plant tissue. 
Second, to understand the mechanisms by which $\mathrm{P}$ fertilizers are efficiently used in the cropping systems (Fig. 2). Four mechanisms are going to be investigated: (1) the soil physiological adsorption and desorption processes, the transformation of chemical speciation processes of fertilizer $\mathrm{P}$ applied in calcareous or acidic soils; (2) and (3) the root and mycorrhizal hyphae driven biological mobilization of legacy $\mathrm{P}$ in soils; (4) the processes of uptake and reutilization of $\mathrm{P}$ in plant.

Third, to establish interventions and methods to achieve the target of high yields and high efficiency with low environmental risk on a broad scale in China. The researches will be conducted in calcareous soil-cropping systems in North China, acidity upland soil-cropping system in South China, the paddy rice-upland crop rotation systems, i.e., rice-vegetable rotation, rice-rape and ricewheat rotations along the Yangtze River region, and the high input vegetable and orchard systems (Fig. 3).

\section{The project}

\subsection{General information}

The project has eight subprojects. Forty-seven principal investigators from 21 institutes in China will be involved under the leadership of Prof. Gu Feng (China Agricultural University). Total funding is nearly 50 million CNY for 2017-2020.

\subsection{Research questions}

The project consists of two main parts based on the research foci we are interested in: the common mechanisms of $\mathrm{P}$ transformation, turnover and use, and $\mathrm{P}$ balance between cropping system and environmental loss in seven cropping zones of China, viz. (1) spring maize system in neutral soil in Northeast China; (2) summer maize-winter wheat rotation in calcareous soil on the North China Plain; (3) summer maize-winter wheat rotation system, cotton and drip irrigation systems with large calcium carbonate concentration and high $\mathrm{pH}$ soils in Northwest China; (4) paddy rice-wheat (or rape or vegetable) rotation systems along the Yangzi River; (5) maize/potato intercropping and (6) maize/soybean intercropping systems in upland acidic soils in South China and Southwest China; (7) high-input vegetable and fruit plantation systems in calcareous or acidic soils in East China. The project will cover 11 soil types and 17 different cropping systems. Three main questions are going to be answered. First, what are the dynamics of transformation, fixation and mobilization of $\mathrm{P}$ fertilizers in the range of cropping systems? Second, what are the mechanisms of soil-crop-microbe interactions by which $\mathrm{P}$ fertilizer can be efficiently used? Third, how to manipulate the high-use processes for $\mathrm{P}$ fertilizer in cropping systems?

\subsection{Subprojects}

2.3.1 The general mechanisms of high $\mathrm{P}$ use in cropping systems

Work package 1: mechanisms of transformation in fractions of fertilizer $P$ across multiple interfaces in soil Led by Prof. Xionghan Feng, Huazhong Agricultural

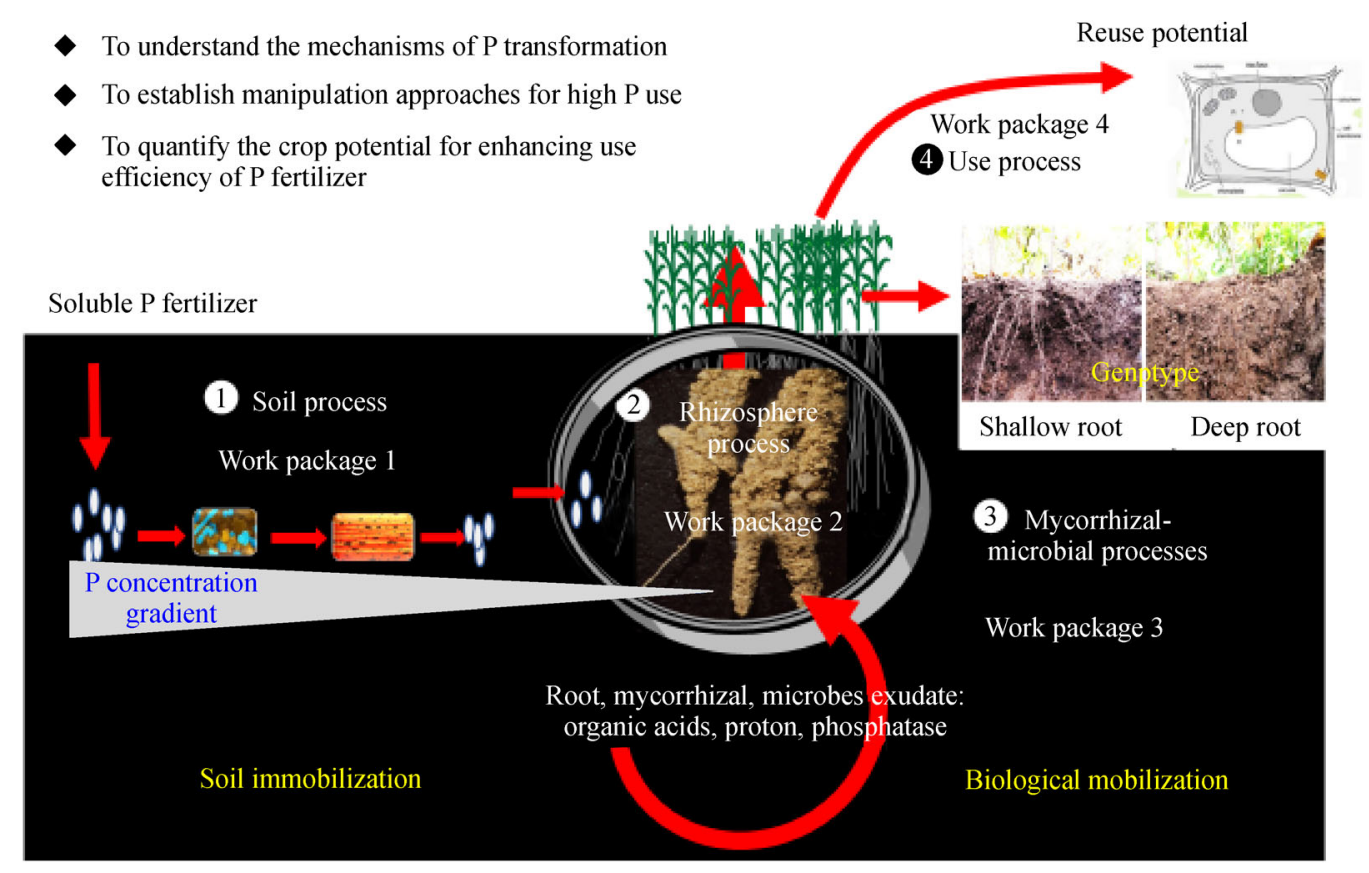

Fig. 2 Illustration of key tasks and objectives of work package 1-4 of the P project. 
- To quantify P allocation in soil-crop system basing on in- and output balance

- To uncover the coupling mechanism among P fertilizer, soils, cropping system

- To propose limiting criteria for maximum application rate of $\mathrm{P}$ fertilizer in main soil-cropping regions in China

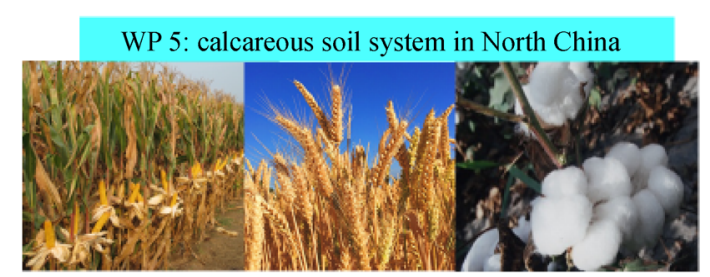

North China soil system

WP 7: acidity soil system in South China

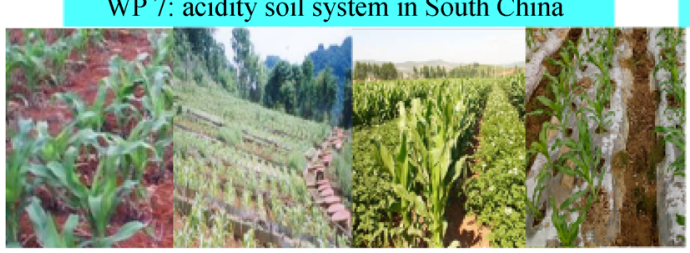

Acid soil system

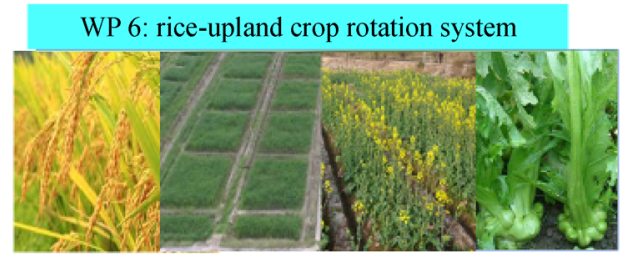

Rice-upland crops (rape, wheat, vegetable) rotation

WP 8: high-input vegetable and orchard systems

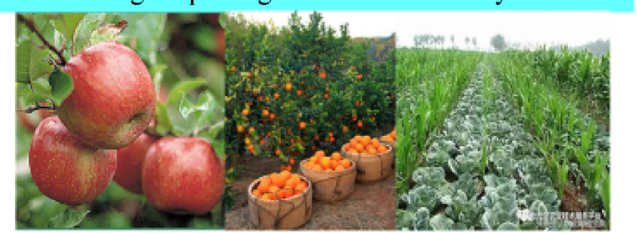

High input system

Fig. 3 Illustration of key tasks and objectives of work package (WP) 5-8 of the P project.

\section{University, China}

Fertilizer $\mathrm{P}$ applied to soil is rapidly transformed into different forms in soil $\mathrm{P}$ pools through physical, chemical and biological reactions ${ }^{[15]}$. The reactions, migration and transformation of fertilizer $\mathrm{P}$ in soil determines its effectiveness and environmental behavior ${ }^{[16]}$. At present, the research on the interaction between $\mathrm{P}$ and soil minerals is mainly focused on the characteristics and mechanism of the reaction between $\mathrm{P}$ and soil minerals, and the speciation of soil $\mathrm{P}$ is usually described by sequential extraction with chemical reagents ${ }^{[17]}$. However, this might not truly reflect the in situ speciation of soil P and dynamic processes of phosphorus-soil interface reactions, which limits the elucidation of the coupling mechanism between $\mathrm{P}$ reaction and $\mathrm{P}$ diffusion/migration. Therefore, it is a challenge to reduce the loss of availability of water-soluble fertilizer $\mathrm{P}$ by effectively regulating $\mathrm{P}$ activation-fixation process in soils of different regions and cropping systems. Focusing on this challenge, the concept of this subproject is to uncover the distribution and spatial-temporal evolution of phosphate speciation in soils at the molecular scale using kinetics and thermodynamics, modern spectroscopy, in situ experimental techniques, isotope tracer methods and quantitative model construction. Typical soils in the main agricultural areas of intensive cropping systems in China will be covered (e.g., black soil in Northeast China, fluvoaquic soil in North China, paddy soil in the middle and lower reaches of the Yangtze River, and red soil in South China). The main factors that drive the interface reactions between different soil types and fertilizer P, and their effects on phosphorus activation-fixation processes will be explored. A mechanistic model based on fertilizer P-soil colloid interface reactions will be constructed by combining speciation analysis and equilibrium calculation. A quantitative transport model of $\mathrm{P}$ fertilizer will be established by combining $\mathrm{P}$ speciation analysis and diffusion equations in order to clarify the effects of physical and chemical characteristics of soils, cropping and management modes on fertilizer $\mathrm{P}$ transfer and loss.

Work package 2: rhizosphere processes and management toward high P use efficiency

Led by Associate Prof. Haigang Li, China Agricultural University, China

The rhizosphere is critical for improving $\mathrm{P}$ use efficiency in soil-crop systems ${ }^{[15]}$. Capacity for P mobilization varies greatly between plant species ${ }^{[6,18]}$. Crops can change the processes of soil $\mathrm{P}$ transformation through rhizosphere processes, leading to increases in soil $\mathrm{P}$ bioavailability, and enhanced crop P uptake ${ }^{[19]}$.

This subproject aims to explore the mechanisms of $\mathrm{P}$ mobilization and $\mathrm{P}$ uptake improvement by rhizosphere processes and regulation in typical soil-crop systems. Research aims are: to explore the spatial-temporal pattern of soil and fertilizer P transformation; to understand the reinforcement mechanism of rhizosphere processes for blocking fertilizer P fixation and remobilizing the blocked fertilizer P; to create rhizosphere manipulating approaches to match fertilizer $\mathrm{P}$ and soil properties for reducing fertilize $\mathrm{P}$ input and increasing $\mathrm{P}$ use efficiency in typical cropping systems.

Work package 3: soil microbe and mycorrhiza fungi mediated P uptake of crop

Led by Prof. Gu Feng, China Agricultural University, China

Transformation of $\mathrm{P}$ fractions in soil is simultaneously affected by soil microbes, such as mycorrhizal fungi, Psolubilizing bacteria and rhizobia ${ }^{[20-22]}$. Microbes enhance the ability of plants to obtain soil P through their metabolic 
processes and turnover, or by forming symbiotic relationships with plant roots ${ }^{[23]}$. More than $40 \%$ of soil microbes can mobilize sparingly soluble $\mathrm{P}$ and convert it into microbial biomass $\mathrm{P}$, and thereby form microbial biomass $\mathrm{P}$ pools in soils. There are also substantial amounts of native mycorrhizal fungi in cropping soil ${ }^{[24]}$, which provide another important pathway for plants to obtain $\mathrm{P}^{[25]}$. Over a long time, many previous studies have shown that microbes enhance root $\mathrm{P}$ uptake, but the contribution of these microbes to crop P uptake is seldom quantified under field conditions.

This subproject aims to study the mechanism by which soil microbes, including mycorrhizal fungi and phosphorus solubilizing bacteria (PSB), promote fertilizer $\mathrm{P}$ use efficiency by crops. Based on understanding of the mechanism of $\mathrm{P}$ mobilization by soil microbes, a new intervention, namely carbon priming, will be established to strengthen soil microbial activity and promote the conversion of sparingly soluble $\mathrm{P}$ to plant bioavailable $\mathrm{P}$, and promote high efficiency use by crops. These findings will provide theoretical and technical support for the application of soil microbes for $\mathrm{P}$ efficient crop production.

Work package 4: mechanism of $P$ use efficiency in plant Led by Prof. Keke Yi, Institute of Agricultural Resource and Regional Plan, Chinese Academy of Agricultural Sciences, China

There are genotypic differences in $\mathrm{P}$ uptake and use efficiency in crops and a few genes involved in highefficiency $\mathrm{P}$ uptake and transport have been cloned successively, with OSSPDT modulating the transport of $\mathrm{P}$ from straw to grain ${ }^{[26]}$ and OSPSTOL1 promoting root growth in rice under upland condition, thereby improving the $\mathrm{P}$ uptake ${ }^{[27]}$. However, the mechanism of efficient $\mathrm{P}$ use in crops is still unclear.

This subproject aims to explore the root characteristics associated with high P-absorption ability, the critical period of $\mathrm{P}$ demand and the $\mathrm{P}$ threshold to maintain growth in crops. By exploring the mechanisms of $\mathrm{P}$ absorption and distribution in plants, the crop genotypes with efficient $\mathrm{P}$ absorption and use will be revealed, which could provide a theoretical basis for setting standards to limit $\mathrm{P}$ fertilizer application in regional crop systems.

2.3.2 Regional approaches for highly efficient $\mathrm{P}$ use and reducing loss of fertilizer $\mathrm{P}$

Work package 5: calcareous soil and cropping systems in North China

Led by Prof. Jialong Lv, Northwest A\&F University, China

Calcareous soils in North China are characterized by high $\mathrm{pH}$, strong $\mathrm{P}$ fixation, and low fertilizer $\mathrm{P}$ use efficiency. Previous studies on the transformation mechanisms and migration processes of $\mathrm{P}$ in soil and for fertilizer $\mathrm{P}$ have not been systematic. Moreover, regulatory technol- ogies for fertilizer-soil-crop matching for efficient use of $\mathrm{P}$ fertilizer are lacking.

Therefore, this subproject aims to determine the soil $\mathrm{P}$ form, transformation, capacity and strength characteristics in four main cropping systems, viz., spring maize, wheatmaize rotation, drip irrigated cotton and potato in Northeast, North and Northwest China, respectively. Pathways for loss in fertilizer P availability, P uptake by crops, $\mathrm{P}$ remaining in field and $\mathrm{P}$ losses (leaching from the root zone and runoff from farmland) and fertilizer $\mathrm{P}$ transformation within $\mathrm{P}$ fractions will be quantified on a regional scale across different soil calcium carbonate concentration gradients in North China.

Work package 6: rice-upland crop rotation systems along the Yangtze river basin

Led by Prof. Yiyong Zhu, Nanjing Agricultural University, China

Rotation of paddy rice with upland crops is the typical cropping system in the Yangtze River basin. The upland crops are mainly wheat, oilseed rape and various vegetables, according to the established agricultural practices and locations along the Yangtze River. The consequent flooding and drying rotation of soils creates strong variation in reduction and oxidation conditions, which affects both the availability and supply of fertilizer $P$ in both the paddy rice and the upland crops. Fertilizer P consumption in the Yangtze River basin represents about $37 \%$ of the total fertilizer P consumption in China, which is relatively large compared to other regions and has caused significant accumulation of $\mathrm{P}$ in agricultural soils in this region. In addition, the annual precipitation in the Yangtze River basin is much greater than in other regions, which leads to a strong P flux from farmlands into the surface water systems and has caused increased $\mathrm{P}$ concentration in the Yangtze River over the last four decades.

This subproject will elucidate the mechanisms of the transformation in $\mathrm{P}$ fractions and use efficiency of various $P$ fertilizers under various paddy rice-upland crops rotation practices. Meanwhile, the processes of biological interactions, i.e., $\mathrm{P}$ acquisition strategies of crop roots and $\mathrm{P}$ mobilization and turnover mechanisms by soil microorganisms, will be quantified. Accordingly, new approaches will be developed to improve $\mathrm{P}$ fertilizer management.

Work package 7: soil acidity and cropping systems in South China

Leading by Prof. Li Tang, Yunnan Agricultural University, China

South China, including the Southwest and South regions, is characterized by high annual precipitation $(>1000 \mathrm{~mm}$ ), wide distribution of acidic upland soil and diverse cropping patterns. High $P$ fertilizer application rate causes low $\mathrm{P}$ use efficiency and high environmental pollution risk, through soil runoff, while the low soil $\mathrm{pH}$ 
and high concentration of $\mathrm{Al} / \mathrm{Fe}$ oxide and hydroxide cause rapid and strong fixation of fertilizer $\mathrm{P}$ in soils. The main challenge for fertilizer P management in this area is how to improve the availability and reduce the loss of fertilizer $\mathrm{P}$ after application to the soil.

Therefore, this subproject aims to quantitatively describe the $\mathrm{P}$ pools of upland acidic soil; to uncover the dynamics of transformations in $\mathrm{P}$ fractions and loss of the availability of fertilizer $\mathrm{P}$ with time; to understand how to match the properties of the $P$ fertilizer with the nature of soils and the demands of crops; to create new techniques for improved efficiency of fertilizer P use by crops and reduced environmental risk in acidic soils.

\section{Work package 8: high-input vegetable and orchard cropping systems}

Led by Associate Prof. Yilin Li, Institute of Soil Science, Chinese Academy of Sciences, China

Large inputs of $\mathrm{P}$ fertilizer, especially as animal manure, have led to accumulation of fertilizer $\mathrm{P}$ in soils and an imbalance between soil carbon and $\mathrm{P}$ in vegetable fields and orchards. The small P-absorption capacity of the limited root systems of some vegetables and fruit trees have further increased the inefficiency of applied $\mathrm{P}$ in these soils. Large P (especially organic P) surplus in soil has intensified the hazard of environmental pollution through runoff and leaching, and further reduced fertilizer $\mathrm{P}$ use efficiency.

This subproject aims to reveal the loss pathways and migration threshold of fertilizer $\mathrm{P}$ and manure $\mathrm{P}$ applied to soil in vegetable fields and orchards. Four typical regions of the high-input cropping systems including vegetables and fruit trees in China have been selected, i.e., (1) open field vegetables in the Taihu Lake zone and greenhouse vegetable field in Shanghai in East China; (2) greenhouse vegetables and apple orchards on the Jiaodong Peninsula, Shandong Province in East China; (3) citrus orchards in the upper Yangtze River, Chongqing in Southwest China; (4) chewing sugarcane fields in Guangdong Province in South China. The research aims are: to conduct large scale surveys of the current status of soil $\mathrm{P}$ pools and problems in $\mathrm{P}$ fertilization management in the typical regions of highinput planting systems; to understand the response of root morphological and physiological characteristics to $\mathrm{P}$ application rate in vegetables and fruit trees; to quantify the response of biomass production and quality of typical vegetable and fruit tree species to soil available P supply gradients and to clarify the critical levels of soil available $\mathrm{P}$ and optimal $\mathrm{P}$ fertilization rate; and, to create novel approaches to reduce $\mathrm{P}$ input and increase $\mathrm{P}$ use efficiency by matching the properties of $\mathrm{P}$ fertilizer with the nature of soils and the demands of the vegetable or fruit tree crops, by regulating soil carbon and $\mathrm{P}$ ratios by localizing application of $\mathrm{P}$ fertilizer at critical growing stage. Finally, four draft standards for the limitation of $\mathrm{P}$ fertilizer application will be proposed to alleviate the conflict between high-input of $\mathrm{P}$ and high-cost of environment in vegetable and fruit tree planting systems.

Acknowledgements We are thankful for financial support provided by the National Key Research and Development Program of China (2017YFD0200200).

Compliance with ethics guidelines Gu Feng, Jingping Gai, Xionghan Feng, Haigang Li, Lin Zhang, Keke Yi, Jialong Lv, Yiyong Zhu, Li Tang, and Yilin Li declare that they have no conflicts of interest or financial conflicts to disclose.

This article does not contain any studies with human or animal subjects performed by any of the authors.

\section{References}

1. Wang F, Sims J T, Ma L, Ma W, Dou Z, Zhang F. The phosphorus footprint of China's food chain: implications for food security, natural resource management, and environmental quality. Journal of Environmental Quality, 2011, 40(4): 1081-1089

2. Food and Agriculture Organization of the United Nations/The International Fund for Agricultural Development/United Nations International Children's Emergency Fund/World Food Programme/ World Health Organization. The State of Food Security and Nutrition in the World 2018. Building climate resilience for food security and nutrition. Rome: FAO, 2018. Licence: CC BY-NC-SA 3.0 IGO

3. Jiao X, Lyu Y, Wu X, Li H, Cheng L, Zhang C, Yuan L, Jiang R, Jiang B, Rengel Z, Zhang F, Davies W J, Shen J. Grain production versus resource and environmental costs: towards increasing sustainability of nutrient use in China. Journal of Experimental Botany, 2016, 67(17): 4935-4949

4. Zhang F S, Wang J Q, Zhang W F, Cui Z L, Ma W Q, Chen X P, Jiang R F. Nutrient use efficiencies of major cereal crops in China and measures for improvement. Acta Pedologica Sinica, 2008, 45 (4): 915-924 (in Chinese)

5. Zhang F S, Cui Z L, Chen X P, Ju X T, Shen J B, Chen Q, Liu X J, Zhang W F, Mi G H, Fan M S, Jiang R F. Integrated nutrient management for food security and environmental quality in China. Advances in Agronomy, 2012, 116(1): 1-40

6. Li H G, Zhang F S, Rengel Z, Shen J B. Rhizosphere properties in monocropping and intercropping systems between faba bean (Vicia faba L.) and maize (Zea mays L.) grown in a calcareous soil. Crop \& Pasture Science, 2013, 64(10): 976-984

7. MacDonald G K, Bennett E M, Potter P A, Ramankutty N. Agronomic phosphorus imbalances across the world's croplands. Proceedings of the National Academy of Sciences of the United States of America, 2011, 108(7): 3086-3091

8. Zhang W F, Ma W Q, Ji Y X, Fan M S, Oenema O, Zhang F S. Efficiency, economics, and environmental implications of phosphorus resource use and the fertilizer industry in China. Nutrient Cycling in Agroecosystems, 2008, 80(2): 131-144

9. Shen J B, Cui Z L, Miao Y X, Mi G H, Zhang H Y, Fan M S, Zhang C C, Jiang R F, Zhang W F, Li H G, Chen X P, Li X L, Zhang F S. Transforming agriculture in China: from solely high yield to both high yield and high resource use efficiency. Global Food Security- 
Agriculture Policy Economics and Environment, 2013, 2(1): 1-8

10. Ministry of Environmental Protection of People's Republic of China. Report on the State of the Environment in China. 2010

11. Gilbert N. Environment: the disappearing nutrient. Nature, 2009, 461(7265): 716-718

12. Cao N, Chen X P, Cui Z L, Zhang F S. Change in soil available phosphorus in relation to the phosphorus budget in China. Nutrient Cycling in Agroecosystems, 2012, 94(2-3): 161-170

13. Feng G Y M, Bai D, Huang Q. Study on changes in fractions and availability of phosphorus in calcareous soil by $32 \mathrm{P}$ tracer method. Acta Pedologica Sinica, 1996, 33(3): 301-307 (in Chinese)

14. Li H, Huang G, Meng Q, Ma L, Yuan L, Wang F, Zhang W, Cui Z, Shen J, Chen X, Jiang R, Zhang F. Integrated soil and plant phosphorus management for crop and environment in China. A review. Plant and Soil, 2011, 349(1-2): 157-167

15. Shen J, Yuan L, Zhang J, Li H, Bai Z, Chen X, Zhang W, Zhang F. Phosphorus dynamics: from soil to plant. Plant Physiology, 2011, 156(3): 997-1005

16. Hesterberg D. Macroscale chemical properties and X-Ray absorption spectroscopy of soil phosphorus. Developments in Soil Science, 2010, 34(3): 313-356

17. Liu J, Hu Y, Yang J, Abdi D, Cade-Menun B J. Investigation of soil legacy phosphorus transformation in long-term agricultural fields using sequential fractionation, P K-edge XANES and solution P NMR spectroscopy. Environmental Science \& Technology, 2015, 49 (1): $168-176$

18. Li H, Shen J, Zhang F, Marschner P, Cawthray G, Rengel Z. Phosphorus uptake and rhizosphere properties of intercropped and monocropped maize, faba bean, and white lupin in acidic soil. Biology and Fertility of Soils, 2010, 46(2): 79-91

19. Li H, Liu J, Li G, Shen J, Bergström L, Zhang F. Past, present, and future use of phosphorus in Chinese agriculture and its influence on phosphorus losses. Ambio, 2015, 44(S2): S274-S285

20. Smith S E, Smith F A. Roles of arbuscular mycorrhizas in plant nutrition and growth: new paradigms from cellular to ecosystem scales. Annual Review of Plant Biology, 2011, 62(1): 227-250

21. Zhang L, Feng G, Declerck S. Signal beyond nutrient, fructose, exuded by an arbuscular mycorrhizal fungus triggers phytate mineralization by a phosphate solubilizing bacterium. ISME Journal, 2018, 12(10): 2339-2351

22. Zhu J, Li M, Whelan M. Phosphorus activators contribute to legacy phosphorus availability in agricultural soils: a review. Science of the Total Environment, 2018, 612(4): 522-537

23. Richardson A E, Simpson R J. Soil microorganisms mediating phosphorus availability update on microbial phosphorus. Plant Physiology, 2011, 156(3): 989-996

24. Gai J, Gao W, Liu L, Chen Q, Feng G, Zhang J, Christie P, Li X. Infectivity and community composition of arbuscular mycorrhizal fungi from different soil depths in intensively managed agricultural ecosystems. Journal of Soils and Sediments, 2015, 15(5): 12001211

25. Smith S E, Smith F A, Jakobsen I. Mycorrhizal fungi can dominate phosphate supply to plants irrespective of growth responses. Plant Physiology, 2003, 133(1): 16-20

26. Yamaji N, Takemoto Y, Miyaji T, Mitani-Ueno N, Yoshida K T, Ma $\mathrm{J}$ F. Reducing phosphorus accumulation in rice grains with an impaired transporter in the node. Nature, 2017, 541(7635): 92-95

27. Gamuyao R, Chin J H, Pariasca-Tanaka J, Pesaresi P, Catausan S, Dalid C, Slamet-Loedin I, Tecson-Mendoza E M, Wissuwa M, Heuer S. The protein kinase Pstoll from traditional rice confers tolerance of phosphorus deficiency. Nature, 2012, 488(7412): 535539 